\title{
Pro-/anti-inflammatory cytokine gene polymorphisms and chronic kidney disease: a cross-sectional study
}

\author{
Rieko Okada ${ }^{1 *}$, Kenji Wakai ${ }^{1}$, Mariko Naito ${ }^{1}$, Emi Morita' ${ }^{1}$ Sayo Kawai ${ }^{1}$, Nobuyuki Hamajima ${ }^{1}$, Megumi Hara ${ }^{2}$, \\ Naoyuki Takashima ${ }^{3}$, Sadao Suzuki ${ }^{4}$, Toshiro Takezaki ${ }^{5}$, Keizo Ohnaka ${ }^{6}$, Kokichi Arisawa $^{7}$, Hiroshi Hirohata ${ }^{8}$, \\ Keitaro Matsuo ${ }^{9}$, Haruo Mikami ${ }^{10}$, Michiaki Kubo ${ }^{11}$ and Hideo Tanaka ${ }^{9}$, for \\ The Japan Multi-Institutional Collaborative Cohort (J-MICC)Study Group
}

\begin{abstract}
Background: The aim of this study was to explore the associations between common potential functional promoter polymorphisms in pro-/anti-inflammatory cytokine genes and kidney function/chronic kidney disease (CKD) prevalence in a large Japanese population.

Methods: A total of 3,323 subjects aged 35-69 were genotyped for all 10 single nucleotide polymorphisms (SNPs) in the promoter regions of candidate genes with minor allele frequencies of $>0.100$ in Japanese populations. The estimated glomerular filtration rate (eGFR) and CKD prevalence (eGFR $<60 \mathrm{ml} / \mathrm{min} / 1.73 \mathrm{~m}^{2}$ ) of the subjects were compared among the genotypes.

Results: A higher eGFR and lower prevalence of CKD were observed for the homozygous variants of IL4 -33CC (high IL-4 [anti-inflammatory cytokine]-producing genotype) and IL6 -572GG (low IL-6 [pro-inflammatory cytokine]producing genotype). Subjects with $/ L 4 C C+\angle L 6$ GG showed the highest mean eGFR $\left(79.1 \mathrm{ml} / \mathrm{min} / 1.73 \mathrm{~m}^{2}\right)$ and lowest CKD prevalence $(0.0 \%)$, while subjects carrying $I L 4 \pi+I L 6 C C$ showed the lowest mean eGFR $(73.4 \mathrm{ml} / \mathrm{min} /$ $1.73 \mathrm{~m}^{2}$ ) and highest CKD prevalence (17.9\%).

Conclusions: The functional promoter polymorphisms IL4 T-33C (rs2070874) and IL6 C-572G (rs1800796), which are the only SNPs that affect the IL-4 and IL-6 levels in Japanese subjects, were associated with kidney function and CKD prevalence in a large Japanese population.
\end{abstract}

\section{Background}

Chronic kidney disease (CKD) is common and continues to increase. It is a risk factor for end-stage renal disease (ESRD) and is also a strong risk factor for cardiovascular diseases and mortality. A combined effect of environment and genotype determines the risk of CKD [1-3], and cytokine polymorphisms play important roles [3-5].

Cytokines are known to influence atherosclerosis, which causes CKD and subsequent ESRD [6,7]. The balance between pro- and anti-inflammatory cytokines determines the inflammatory response and may mediate the

\footnotetext{
* Correspondence: rieokada@med.nagoya-u.ac.jp

'Department of Preventive Medicine, Nagoya University Graduate School of Medicine, Nagoya, Japan

Full list of author information is available at the end of the article
}

progression of CKD [6]. Among the cytokines, pro-inflammatory (IL-1, IL-6, and TNF- $\alpha$ ) and anti-inflammatory (IL-4, IL-10, and IL-13) cytokines play pivotal roles [6]. IL2 and IL-8 are also well-known pro-inflammatory cytokines that may affect CKD or ESRD progression $[7,8]$. Functional SNPs within the promoter area of these cytokine genes have been identified in that they influence the gene promoter activities and gene product levels $[9,10]$. Such polymorphisms have been demonstrated to be associated with susceptibility to a number of atherosclerotic diseases in CKD [3-5], but the issue of whether these cytokine polymorphisms are risk factors for CKD itself has not been fully clarified. Some studies have failed to show such associations, possibly owing to the small sample sizes, and their conclusions are controversial [11].

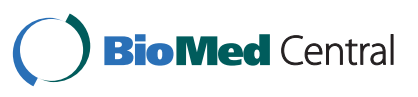

() 2012 Okada et al; licensee BioMed Central Ltd. This is an Open Access article distributed under the terms of the Creative Commons Attribution License (http://creativecommons.org/licenses/by/2.0), which permits unrestricted use, distribution, and reproduction in any medium, provided the original work is properly cited. 
This study aimed to explore the associations between common potential functional promoter polymorphisms of pro-/anti-inflammatory cytokines and kidney function/CKD prevalence in a large Japanese population.

\section{Methods}

\section{Study subjects}

The study subjects were participants in the Japan MultiInstitutional Collaborative Cohort (J-MICC) Study, a large cohort study to confirm and detect gene-environment interactions in lifestyle-related diseases, in which voluntarily enrolled participants aged 35-69 from 10 areas of Japan provided blood and lifestyle data based on questionnaires. The details of the J-MICC Study have been described elsewhere [12]. The participants in this cross-sectional study were 4,519 subjects enrolled in the 10 study areas throughout Japan between 2004 and 2008 [13]. Serum creatinine (SCr) data were available in eight study areas. Of the 3,435 participants in these areas, 3,323 (97\%) subjects were included in the analyses. Informed consent was obtained from all subjects and the study protocol was approved by the ethics committees of Nagoya University School of Medicine and the participating institutions.

\section{Selection and genotyping of polymorphisms}

We selected pro-inflammatory (IL1, IL2, IL6, IL8, and TNFA) and anti-inflammatory (IL4, IL10, and IL13) cytokine genes as candidate genes based on the published literature [6-8]. In addition, $C D 14$, which encodes a lipopolysaccharide receptor that initiates the inflammatory response, was selected based on our previous report [14]. Subsequently, to the best of our knowledge, we selected all the single nucleotide polymorphisms (SNPs) in the promoter regions that had minor allele frequencies in Japanese populations of $>0.100$, based on the database SNP (dbSNP) and the HapMap database, and that had potential functional effects according to the published literature. The selected SNPs were IL4 T33C (rs2070874, which is in complete linkage disequilibrium with T-589C [rs2243250]) [9,15], IL6 C-572(-634) G (rs1800796) [10,11], IL1B T-31C (rs1143627, linked to C-511T [rs16944]), IL2 T-330G (rs2069762), IL13 C$1111 \mathrm{~T}$ (rs1800925) [16], and CD14 A-260(-159)G (rs2569190) [14], which were proven to be functional, and IL8 T-251A (rs4073), IL10 T-819C (rs1800871, linked to A-592C [rs1800872]), TNFA C-857T (rs1799724), and TNFA T-1031C (rs1799964, linked to C-863A [rs1800630]), which were reported to be probable or presumed functional SNPs [16,17]. IL6 T-6331C (rs10499563), A-597G (rs1800797), C-174G (rs1800795), and IL10 A-1082G (rs1800896) were excluded because their minor allele frequencies were $<0.100$.
DNA was extracted from buffy coat fractions using a BioRobot M48 Workstation (Qiagen Group, Tokyo, Japan), or from whole blood using an automatic nucleic acid isolation system (NA-3000; KURABO, Osaka, Japan). The SNPs were genotyped using a Multiplex PCR-based Invader Assay (Third Wave Technologies, Madison, WI) [18] at the Laboratory for Genotyping Development, Center for Genomic Medicine, RIKEN. The genotype call rates were $99.40 \%$ to $99.98 \%$.

\section{Estimated glomerular filtration rate (eGFR), and definitions of CKD and comorbid diseases}

$\mathrm{SCr}$ was measured in all participants using an enzymatic method. The eGFR of each participant was calculated from the $\mathrm{SCr}$, age, and sex using the following Japanese eGFR equation recently determined by the Japanese Society of Nephrology [19]:

$$
\operatorname{eGFR}\left(\mathrm{ml} / \mathrm{min} / 1.73 \mathrm{~m}^{2}\right)=194 \times \mathrm{SCr}(\mathrm{mg} / \mathrm{dl})^{-1.094} \times \operatorname{age}^{-0.287}(\times 0.739 \text { if female }) .
$$

The prevalence of CKD was determined for CKD stages 3-5 (defined as eGFR $<60 \mathrm{ml} / \mathrm{min} / 1.73 \mathrm{~m}^{2}$ ) [20].

Hypertension was defined as resting blood pressure $\geq$ $140 / 90 \mathrm{mmHg}$ or being under treatment for hypertension. Diabetes mellitus was defined as fasting blood glucose $\geq 126 \mathrm{mg} / \mathrm{dl}$ or serum HbA1c $\geq 6.5 \%$ or being under treatment for diabetes mellitus.

\section{Statistical analysis}

The genotype distributions were tested for Hardy-Weinberg equilibrium. One-way analysis of variance (ANOVA) or the $\chi^{2}$ test was used for comparisons of mean eGFRs and CKD prevalences between genotypes, and the polymorphisms with a significant difference in the mean eGFR or CKD prevalence were selected for multivariate analyses. The mean eGFRs, adjusted for age (continuous variable), sex, comorbid hypertension and diabetes mellitus, and history of cardiovascular diseases by multiple linear regression models, were compared between genotypes using the homozygous for the major allele as the reference. Odds ratios (ORs) for CKD prevalence adjusted for these covariates were estimated by unconditional logistic regression analysis with $95 \%$ confidence intervals (CIs). Standard errors were adjusted for the study areas. The analyses were carried out using STATA ver. 9 software (StataCorp, College Station, TX).

\section{Results}

The characteristics and the genotype frequencies of the subjects are summarised in Table 1 and Table 2. Seven subjects had a history of kidney disease, and two were categorised into the CKD group. The genotype frequencies were in Hardy-Weinberg equilibrium (data not shown), except for IL6 C-572G (57.5\% for CC, 35.7\% for CG, and 
Table 1 Clinical characteristics of study subjects

\begin{tabular}{|c|c|c|c|}
\hline & $\begin{array}{c}\text { CKD } \\
(n=546)\end{array}$ & $\begin{array}{l}\text { Non-CKD } \\
(n=2,777)\end{array}$ & $\begin{array}{c}\text { Total } \\
(\mathrm{n}=3,323)\end{array}$ \\
\hline Age (years) & $60.6 \pm 7.2$ & $55.9 \pm 8.7$ & $56.7 \pm 8.6$ \\
\hline Male & $252(46.2 \%)$ & $1,364(49.1 \%)$ & $1,616(48.6 \%)$ \\
\hline Body mass index & $23.5 \pm 3.1$ & $23.4 \pm 3.3$ & $23.4 \pm 3.3$ \\
\hline Hypertension & $245(44.9 \%)$ & $1,050(37.8 \%)$ & $1,295(39.0 \%)$ \\
\hline Systolic blood pressure (mm Hg) & $130.5 \pm 19.8$ & $128.1 \pm 19.3$ & $128.5 \pm 19.4$ \\
\hline Diastolic blood pressure $(\mathrm{mm} \mathrm{Hg})$ & $79.1 \pm 12.4$ & $78.6 \pm 11.9$ & $78.7 \pm 12.0$ \\
\hline Anti-hypertensive medication & $146(26.7 \%)$ & $503(18.1 \%)$ & $649(19.5 \%)$ \\
\hline Diabetes mellitus & $54(9.9 \%)$ & $220(7.9 \%)$ & $274(8.2 \%)$ \\
\hline Fasting plasma glucose (mmol/l) & $5.49 \pm 1.23$ & $5.55 \pm 1.17$ & $5.54 \pm 1.17$ \\
\hline $\mathrm{HbA1c}(\%)$ & $5.22 \pm 0.69$ & $5.22 \pm 0.66$ & $5.22 \pm 0.67$ \\
\hline Glucose-lowering medication & $28(5.1 \%)$ & $117(4.2 \%)$ & $145(4.4 \%)$ \\
\hline Cardiovascular diseases & $34(6.2 \%)$ & $80(2.9 \%)$ & $114(3.4 \%)$ \\
\hline Total cholesterol (mmol/l) & $5.66 \pm 0.88$ & $5.46 \pm 0.83$ & $5.50 \pm 0.88$ \\
\hline HDL cholesterol (mmol/l) & $1.60 \pm 0.41$ & $1.64 \pm 0.42$ & $1.63 \pm 0.42$ \\
\hline Lipid-lowering medication & $68(12.5 \%)$ & 233(8.4\%) & $301(9.1 \%)$ \\
\hline Uric acid $(\mu \mathrm{mol} / \mathrm{l})$ & $333 \pm 89$ & $303 \pm 77$ & $309 \pm 83$ \\
\hline Current smokers & $68(12.5 \%)$ & 495(17.8\%) & $563(16.9 \%)$ \\
\hline
\end{tabular}

Results are expressed as mean \pm SD or number (\%). CKD = chronic kidney disease. CKD is defined by eGFR $<60 \mathrm{ml} / \mathrm{min} / 1.73 \mathrm{~m}{ }^{2}$. Hypertension $=$ blood pressure $\geq 140 / 90 \mathrm{mmHg}$ or under anti-hypertensive medication. Diabetes mellitus = fasting blood glucose $\geq 126 \mathrm{mg} / \mathrm{dl}, \mathrm{HbA} 1 \mathrm{c} \geq 6.5 \%$ or under glucose-lowering medication.

6.8\% for GG, $\mathrm{P}=0.026$, in comparison with the expected values of $57.2 \%, 36.9 \%$, and $5.9 \%$, respectively) [13].

The mean eGFRs and CKD prevalences were compared among the genotypes of the 10 cytokine SNPs (Table 3). The mean eGFRs differed for the IL4 T-33C (rs2070874) and IL6 C-572G (rs1800796) genotypes (P = 0.012 and $P=0.004$, respectively), while the CKD prevalences differed for the IL4 T-33C genotypes. Thus, the IL 4 and IL6 genotypes were subjected to multivariate analyses.

Higher eGFRs and lower CKD prevalences were observed for the IL4 -33CC and IL6 -572GG genotypes (Table 4). The mean eGFRs were 75.7 and $73.4 \mathrm{ml} / \mathrm{min} /$ $1.73 \mathrm{~m}^{2}$ for the IL4 CC and TT genotype carriers, and 76.9 and $74.2 \mathrm{ml} / \mathrm{min} / 1.73 \mathrm{~m}^{2}$ for the IL6 GG and CC genotype carriers, respectively. The CKD prevalences were $11.4 \%$ and $17.8 \%$ for the IL4 CC and TT genotype carriers $(\mathrm{OR}=0.59,95 \% \mathrm{CI}=0.37-0.95, \mathrm{P}=0.029$ after adjustment), and $11.6 \%$ and $16.3 \%$ for the IL6 GG and CC genotype carriers $(\mathrm{OR}=0.67,95 \% \mathrm{CI}=0.50-0.90, \mathrm{P}$ $=0.008$ after adjustment), respectively. These differences were greater when the two genotypes were combined (Table 5). Subjects with both the IL4 CC and IL6 GG genotypes showed the highest mean eGFR $(79.1 \mathrm{ml} /$ $\min / 1.73 \mathrm{~m}^{2}$ ) and lowest CKD prevalence (0.0\%), while subjects carrying both the IL4 TT and IL6 CC genotypes showed the lowest mean eGFR $\left(73.4 \mathrm{ml} / \mathrm{min} / 1.73 \mathrm{~m}^{2}\right)$ and highest CKD prevalence (17.9\%). There was no interaction between the IL4 CC and IL6 GG genotypes, and their effects were additive.
We previously reported an association between the CD14 A-260G SNP and kidney function among a population living in the north part of Japan using an eGFR derived from the MDRD Study equation [14]. However, the present study did not show such an association.

\section{Discussion}

Our explorations revealed that the subjects with the genotypes IL4 -33CC (a genotype that produces high levels of IL-4) and IL6 -572GG (a genotype that produces low levels of IL-6) had better kidney function and a lower risk of CKD in a large Japanese population.

Cytokines are important modulators of inflammation, and the balance between pro- and anti-inflammatory cytokines determines the inflammatory response and may mediate the progression of atherosclerosis and subsequent CKD [6,7]. Genetic polymorphisms of these cytokines have been shown to be associated with comorbidities, such as cardiovascular disease, in ESRD patients [3-5], or with ESRD susceptibility [8], but there are controversial results that no polymorphisms of the IL6, IL10, and IL1 genes were associated with ESRD [11]. The evidence for polymorphisms in cytokine genes affecting the risk of CKD itself is scarce and this issue has not been fully clarified, especially in the general population.

IL-4 is an anti-inflammatory cytokine that exerts immunosuppressive effects on macrophages and suppresses pro-inflammatory cytokine production [21]. The promoter polymorphism IL4 T-33C (which is in complete linkage disequilibrium with $I L 4$ T-589C) affects IL- 
Table 2 Genotype frequencies of study subjects

\begin{tabular}{|c|c|c|c|}
\hline Genotype & $\begin{array}{c}\text { CKD } \\
(n=546)\end{array}$ & $\begin{array}{c}\text { non-CKD } \\
(n=2,777)\end{array}$ & $\begin{array}{c}\text { Total } \\
(n=3,323)\end{array}$ \\
\hline \multicolumn{4}{|c|}{ IL1B T-31C (rs1143627) } \\
\hline $\mathrm{TT}$ & $163(29.9 \%)$ & $791(28.5 \%)$ & 954 (28.7\%) \\
\hline C T & $266(48.7 \%)$ & $1,355(48.8 \%)$ & $1,621(48.8 \%)$ \\
\hline $\mathrm{CC}$ & 117 (21.4\%) & $631(22.7 \%)$ & $748(22.5 \%)$ \\
\hline \multicolumn{4}{|c|}{ IL2 T-330G (rs2069762) } \\
\hline $\mathrm{TT}$ & $244(44.9 \%)$ & $1,225(44.1 \%)$ & $1,469(44.2 \%)$ \\
\hline$T G$ & $241(44.3 \%)$ & $1,239(44.6 \%)$ & $1,480(44.6 \%)$ \\
\hline G G & 59 (10.9\%) & 312 (11.2\%) & $371(11.2 \%)$ \\
\hline \multicolumn{4}{|l|}{ IL4 T-33C (rs2070874) } \\
\hline $\mathrm{TT}$ & $259(47.4 \%)$ & 1,193 (43.0\%) & $1,452(43.7 \%)$ \\
\hline $\mathrm{TC}$ & $241(44.1 \%)$ & $1,226(44.2 \%)$ & $1,467(44.2 \%)$ \\
\hline$C C$ & $46(8.4 \%)$ & $357(12.9 \%)$ & $403(12.1 \%)$ \\
\hline \multicolumn{4}{|c|}{ IL6 C-572G (rs1800796) } \\
\hline$C \mathrm{C}$ & $312(57.1 \%)$ & $1,600(57.6 \%)$ & $1,912(57.6 \%)$ \\
\hline GC & $208(38.1 \%)$ & 977 (35.2\%) & $1,185(35.7 \%)$ \\
\hline G G & $26(4.8 \%)$ & $199(7.2 \%)$ & $225(6.8 \%)$ \\
\hline \multicolumn{4}{|l|}{ IL8 T-251A (rs4073) } \\
\hline $\mathrm{TT}$ & $254(46.5 \%)$ & $1,281(46.5 \%)$ & $1,535(46.5 \%)$ \\
\hline A T & $235(43.0 \%)$ & $1,204(43.7 \%)$ & $1,439(43.6 \%)$ \\
\hline A A & $57(10.4 \%)$ & $273(9.9 \%)$ & $330(10.0 \%)$ \\
\hline \multicolumn{4}{|c|}{ IL10 T-819C (rs1800871) } \\
\hline T T & $252(46.2 \%)$ & $1,175(42.5 \%)$ & $1,427(43.1 \%)$ \\
\hline C T & $239(43.8 \%)$ & $1,222(44.2 \%)$ & $1,461(44.1 \%)$ \\
\hline $\mathrm{CC}$ & $55(10.1 \%)$ & $370(13.4 \%)$ & $425(12.8 \%)$ \\
\hline \multicolumn{4}{|c|}{ IL13 C-1111T (rs1800925) } \\
\hline $\mathrm{CC}$ & $370(67.9 \%)$ & $1,847(66.5 \%)$ & $2,217(66.8 \%)$ \\
\hline $\mathrm{TC}$ & $158(29.0 \%)$ & 840 (30.3\%) & $998(30.1 \%)$ \\
\hline $\mathrm{TT}$ & 17 (3.1\%) & $89(3.2 \%)$ & $106(3.2 \%)$ \\
\hline \multicolumn{4}{|c|}{ TNFA C-857T (rs1799724) } \\
\hline$C C$ & $373(68.3 \%)$ & $1,788(64.4 \%)$ & $2,161(65.0 \%)$ \\
\hline $\mathrm{CT}$ & 155 (28.4\%) & 887 (31.9\%) & $1,042(31.4 \%)$ \\
\hline $\mathrm{TT}$ & $18(3.3 \%)$ & $102(3.7 \%)$ & $120(3.6 \%)$ \\
\hline \multicolumn{4}{|c|}{ TNFA T-1031C (rs1799964) } \\
\hline T T & $383(70.2 \%)$ & $1,934(69.6 \%)$ & $2,317(69.7 \%)$ \\
\hline C T & $144(26.4 \%)$ & $764(27.5 \%)$ & $908(27.3 \%)$ \\
\hline $\mathrm{CC}$ & $19(3.5 \%)$ & $79(2.8 \%)$ & 98 (2.9\%) \\
\hline \multicolumn{4}{|c|}{ CD14 T-260C (rs2569190) } \\
\hline $\mathrm{TT}$ & $144(26.4 \%)$ & 785 (28.3\%) & 929 (28.0\%) \\
\hline $\mathrm{TC}$ & $275(50.4 \%)$ & $1,412(50.9 \%)$ & $1,687(50.8 \%)$ \\
\hline$C \mathrm{C}$ & $127(23.3 \%)$ & $580(20.9 \%)$ & 707 (21.3\%) \\
\hline
\end{tabular}

Results are expressed as number (\%). CKD = chronic kidney disease. CKD is defined by eGFR $<60 \mathrm{ml} / \mathrm{min} / 1.73 \mathrm{~m}^{2}$.

4 expression [15], and the CC genotype shows a high level of IL-4 protein [9]. Accordingly, subjects with the $\mathrm{CC}$ genotype showed a lower risk of ischemic stroke relapse [22], consistent with our data indicating a lower risk of CKD in CC genotype carriers.

An elevated level of the main pro-inflammatory cytokine IL-6 predicts cardiovascular mortality in ESRD patients [3]. The IL6 C to $\mathrm{G}$ variation at position -572 reduces the transcriptional activity of the IL6 promoter, and the levels of IL- 6 are lower in carriers of the IL6 -572GG genotype [10,11]. Accordingly, the IL6 -572GG genotype was associated with lower risks of kidney allograft survival [23] and abdominal aortic aneurysm [24], consistent with our data showing a lower risk of CKD in GG genotype carriers.

The combined effect of high IL-4- and low IL-6-producing genotypes has been shown to lead to a lower risk of ESRD [8]. We also found that no CKD subjects carried high IL-4- and low IL-6-producing (low-risk) genotypes, and that their mean eGFR was $5.2 \mathrm{ml} / \mathrm{min} /$ $1.73 \mathrm{~m}^{2}$ higher than that in carriers of the low IL-4- and high IL-6-producing (high-risk) genotypes. This difference is almost equivalent to a 14-year difference in a healthy Japanese population [25], and has a significant impact with respect to cardiovascular disease prevention, especially among healthy individuals who are not aware of a possible risk of CKD.

The evidence for polymorphisms in cytokine genes affecting the risk of CKD is scarce. No cytokine genes were identified as susceptibility loci for CKD in a Caucasian population in a genome-wide association study (GWAS) [1]. However, this may simply mean that no cytokine genes were highly statistically significantly associated in the context of the multiple testing related to the GWAS, and therefore not presented in the GWAS report. Yoshida et al. [2] showed that some genetic variants were associated with CKD in a large Japanese population, but only TNFA and IL10 were included as representative cytokine genes and did not show associations. In contrast, we selected candidate genes that are assumed to be of physiological interest based on the associations between pro-/anti-inflammatory cytokines and CKD [6,7]. The other difference is that the former study participants were mixed, and comprised patients with various symptoms, health check-up examinees and aged subjects [2]. In contrast, our study participants were enrolled from the population with an age range of 35 to 69 . Thus, our study contains the largest general Japanese population investigated to date for associations among pro-/anti-inflammatory cytokine gene variants and CKD.

No haplotype analyses were needed because IL4 T$33 \mathrm{C}$ and IL6 C-572G are the only SNPs that affect the IL-4 and IL-6 levels in Japanese subjects. IL4 T-589C, IL4 T-33C, and a 70-bp variable number of tandem repeat polymorphism (VNTR) within intron 3 are in complete linkage disequilibrium, thus there are only two IL4 gene haplotypes in Japanese populations; -589T/33T/B1 (183 bp) (allele frequency, 0.670) and $-589 \mathrm{C} /-$ 33C/B2 (253 bp) (0.330) [15]. In addition, IL6 transcription is influenced by four promoter polymorphisms (C- 
Table 3 Mean eGFRs and CKD prevalence with respect to cytokine polymorphism genotypes

\begin{tabular}{|c|c|c|c|c|c|c|}
\hline \multirow[t]{2}{*}{ Genotype } & \multirow[t]{2}{*}{$\mathbf{n}$} & \multicolumn{2}{|c|}{ eGFR $\left(\mathrm{ml} / \mathrm{min} / 1.73 \mathrm{~m}^{2}\right)$} & \multicolumn{3}{|c|}{ CKD $\left(\right.$ eGFR $\left.<60 \mathrm{ml} / \mathrm{min} / 1.73 \mathrm{~m}^{2}\right)$} \\
\hline & & mean \pm SD & P-value $^{\dagger}$ & $n$ & (\%) & P-value ${ }^{\ddagger}$ \\
\hline \multicolumn{7}{|l|}{ IL1B T-31C (rs1143627) } \\
\hline $\mathrm{TT}$ & 954 & $74.0 \pm 14.9$ & & 163 & $(16.6 \%)$ & \\
\hline$C T$ & 1,621 & $73.9 \pm 14.6$ & 0.576 & 266 & (16.3\%) & 0.727 \\
\hline$C \mathrm{C}$ & 748 & $74.6 \pm 15.3$ & & 117 & $(15.6 \%)$ & \\
\hline \multicolumn{7}{|l|}{ IL2 T-330G (rs2069762) } \\
\hline $\mathrm{TT}$ & 1,469 & $74.0 \pm 14.8$ & & 244 & $(16.6 \%)$ & \\
\hline TG & 1,480 & $74.2 \pm 14.9$ & 0.860 & 241 & (16.3\%) & 0.938 \\
\hline G G & 371 & $74.3 \pm 14.5$ & & 59 & $(15.9 \%)$ & \\
\hline \multicolumn{7}{|l|}{ IL4 T-33C (rs2070874) } \\
\hline $\mathrm{TT}$ & 1,452 & $73.4 \pm 14.6$ & & 259 & $(17.8 \%)$ & \\
\hline $\mathrm{TC}$ & 1,467 & $74.4 \pm 15.1$ & 0.012 & 241 & $(16.4 \%)$ & 0.009 \\
\hline$C \mathrm{C}$ & 403 & $75.8 \pm 14.5$ & & 46 & (11.4\%) & \\
\hline \multicolumn{7}{|l|}{ IL6 C-572G (rs1800796) } \\
\hline $\mathrm{CC}$ & 1,912 & $74.2 \pm 14.7$ & & 312 & (16.3\%) & \\
\hline GC & 1,185 & $73.4 \pm 14.8$ & 0.004 & 208 & $(17.6 \%)$ & 0.082 \\
\hline G G & 225 & $76.9 \pm 15.9$ & & 26 & $(11.6 \%)$ & \\
\hline \multicolumn{7}{|l|}{ IL8 T-251A (rs4073) } \\
\hline $\mathrm{TT}$ & 1,535 & $74.1 \pm 14.4$ & & 254 & (17.3\%) & \\
\hline A T & 1,439 & $73.9 \pm 15.2$ & 0.745 & 235 & (16.3\%) & 0.917 \\
\hline$A A$ & 330 & $74.6 \pm 15.4$ & & 57 & $(16.5 \%)$ & \\
\hline \multicolumn{7}{|l|}{ IL10 T-819C (rs1800871) } \\
\hline $\mathrm{TT}$ & 1,427 & $73.6 \pm 14.7$ & & 252 & (17.7\%) & \\
\hline$C T$ & 1,461 & $74.2 \pm 14.8$ & 0.155 & 239 & $(16.4 \%)$ & 0.070 \\
\hline$C C$ & 425 & $75.2 \pm 15.0$ & & 55 & (12.9\%) & \\
\hline \multicolumn{7}{|c|}{ IL13 C-11111T (rs1800925) } \\
\hline$C C$ & 2,217 & $74.0 \pm 14.9$ & & 370 & $(16.7 \%)$ & \\
\hline $\mathrm{TC}$ & 998 & $74.3 \pm 14.7$ & 0.734 & 158 & $(15.8 \%)$ & 0.827 \\
\hline $\mathrm{TT}$ & 106 & $74.7 \pm 14.3$ & & 17 & (16.0\%) & \\
\hline \multicolumn{7}{|l|}{ TNFA C-857T (rs1799724) } \\
\hline$C C$ & 2,161 & $73.6 \pm 14.7$ & & 373 & (17.3\%) & \\
\hline$C T$ & 1,042 & $74.9 \pm 15.0$ & 0.054 & 155 & $(14.9 \%)$ & 0.212 \\
\hline $\mathrm{TT}$ & 120 & $75.5 \pm 15.4$ & & 18 & $(15.0 \%)$ & \\
\hline \multicolumn{7}{|c|}{ TNFA T-1031C (rs1799964) } \\
\hline $\mathrm{TT}$ & 2,317 & $73.9 \pm 14.6$ & & 383 & $(16.5 \%)$ & \\
\hline$C T$ & 908 & $74.5 \pm 15.4$ & 0.641 & 144 & (15.9\%) & 0.652 \\
\hline$C C$ & 98 & $74.1 \pm 14.6$ & & 19 & (19.4\%) & \\
\hline \multicolumn{7}{|l|}{ CD14 T-260C (rs2569190) } \\
\hline $\mathrm{TT}$ & 929 & $74.5 \pm 14.5$ & & 144 & $(15.5 \%)$ & \\
\hline $\mathrm{TC}$ & 1,687 & $74.2 \pm 14.9$ & 0.226 & 275 & (16.3\%) & 0.403 \\
\hline $\mathrm{CC}$ & 707 & $73.3 \pm 14.9$ & & 127 & $(18.0 \%)$ & \\
\hline
\end{tabular}

${ }^{\dagger} \mathrm{P}$ for ANOVA, ${ }^{\ddagger} \mathrm{P}$ for the $\chi^{2}$ test. eGFR = estimated glomerular filtration rate. CKD = chronic kidney disease. CKD is defined by eGFR $<60 \mathrm{ml} / \mathrm{min} / 1.73 \mathrm{~m}{ }^{2}$. Bold style represents $\mathrm{P}<0.05$.

572G, A-597G, -373AnTn and C-174G) [26], but A$597 \mathrm{G}$ and C-174G do not exist or are very rare in Japanese populations. Only three prevalent haplotypes have been identified in Japanese populations [10]: -572C/373A10T10 (allele frequency 0.733), G/A10T11 (0.136), and G/A9T11 (0.104). The serum levels of IL-6 were high in C/A10T10 and low in both G/A10T11 and G/
A9T11, with no difference between the IL-6 levels in G/ A10T11 and G/A9T11. Thus, IL4 T-33C and IL6 C$572 \mathrm{G}$ could be the only SNPs that affect the transcriptional activity of IL-4 and IL- 6 in Japanese populations.

A limitation of our study was that IL6 C-572G was not in Hardy-Weinberg equilibrium. However, the absolute difference between the actual and expected frequencies 
Table 4 Mean eGFRs and CKD prevalence for IL4 T-33C and IL6 C-572G genotypes

\begin{tabular}{|c|c|c|c|c|c|c|c|c|c|c|}
\hline \multirow[t]{2}{*}{ Genotype } & \multirow[t]{2}{*}{ n } & \multicolumn{4}{|c|}{ eGFR $\left(\mathrm{ml} / \mathrm{min} / 1.73 \mathrm{~m}^{2}\right)$} & \multicolumn{5}{|c|}{ CKD (eGFR $\left.<60 \mathrm{ml} / \mathrm{min} / 1.73 \mathrm{~m}^{2}\right)$} \\
\hline & & mean \pm SD & $\beta^{\dagger}$ & $(95 \% \mathrm{Cl})$ & P-value $^{\dagger}$ & $n$ & (\%) & $\mathrm{OR}^{\dagger}$ & $(95 \% \mathrm{Cl})$ & P-value \\
\hline \multicolumn{11}{|l|}{ IL4 T-33C } \\
\hline$\pi$ & 1,452 & $73.4 \pm 14.6$ & 0 & (reference) & - & 259 & $(17.8 \%)$ & 1 & (reference) & - \\
\hline $\mathrm{TC}$ & 1,466 & $74.4 \pm 15.1$ & 0.9 & $(-1.2-2.9)$ & 0.346 & 241 & $(16.4 \%)$ & 0.91 & $(0.78-1.07)$ & 0.269 \\
\hline $\mathrm{CC}$ & 403 & $75.7 \pm 14.5$ & 2.2 & $(-1.9-6.3)$ & 0.240 & 46 & $(11.4 \%)$ & 0.59 & $(0.37-0.95)$ & 0.029 \\
\hline \multicolumn{11}{|l|}{ IL6 C-572G } \\
\hline $\mathrm{CC}$ & 1,911 & $74.2 \pm 14.7$ & 0 & (reference) & - & 312 & $(16.3 \%)$ & 1 & (reference) & - \\
\hline CG & 1,185 & $73.4 \pm 14.8$ & -1.1 & $(-2.3-0.1)$ & 0.065 & 208 & (17.6\%) & 1.13 & $(0.98-1.31)$ & 0.091 \\
\hline GC & 225 & $76.9 \pm 15.9$ & 2.6 & $(-0.1-5.2)$ & 0.055 & 26 & (11.6\%) & 0.67 & $(0.50-0.90)$ & 0.008 \\
\hline
\end{tabular}

${ }^{\dagger}$ adjusted for age, sex, hypertension, diabetes mellitus, and cardiovascular diseases. Standard errors were adjusted for study areas. eGFR $=$ estimated glomerular filtration rate. CKD = chronic kidney disease. CKD is defined by eGFR $<60 \mathrm{ml} / \mathrm{min} / 1.73 \mathrm{~m}^{2}$.

Table 5 Mean eGFRs and CKD prevalence for IL4 T-33C and IL6 C-572G genotypes combined

\begin{tabular}{|c|c|c|c|c|c|c|c|c|c|c|}
\hline \multirow[t]{2}{*}{ Genotype } & \multirow[t]{2}{*}{$\mathrm{n}$} & \multicolumn{4}{|c|}{ eGFR $\left(\mathrm{ml} / \mathrm{min} / 1.73 \mathrm{~m}^{2}\right)$} & \multicolumn{5}{|c|}{ CKD $\left(\mathrm{eGFR}<60 \mathrm{ml} / \mathrm{min} / 1.73 \mathrm{~m}^{2}\right)$} \\
\hline & & mean $\pm S D$ & $\beta^{\dagger}$ & $(95 \% \mathrm{Cl})$ & P-value $^{\dagger}$ & $\mathrm{n}$ & (\%) & $\mathrm{OR}^{\dagger}$ & $(95 \% \mathrm{Cl})$ & P-value $^{\dagger}$ \\
\hline IL4 TT/ IL6CC & 849 & $73.4 \pm 14.4$ & 0 & (reference) & - & 152 & $(17.9 \%)$ & 1 & (reference) & - \\
\hline IL4 TC/ IL6 CC & 854 & $74.5 \pm 14.9$ & 1.1 & $(-0.3-2.4)$ & 0.108 & 140 & $(16.4 \%)$ & 0.89 & $(0.75-1.06)$ & 0.200 \\
\hline IL4 TT/ IL6CG & 512 & $72.5 \pm 14.5$ & -0.8 & $(-2.8-1.1)$ & 0.337 & 98 & $(19.1 \%)$ & 1.08 & $(0.90-1.30)$ & 0.387 \\
\hline IL4 TC/ IL6CG & 512 & $74.0 \pm 15.2$ & 0.2 & $(-3.1-3.5)$ & 0.890 & 84 & $(16.4 \%)$ & 0.94 & $(0.68-1.28)$ & 0.686 \\
\hline IL4 CC / IL6CG & 161 & $74.0 \pm 14.4$ & 0.3 & $(-3.8-4.4)$ & 0.867 & 26 & $(16.1 \%)$ & 0.89 & $(0.42-1.90)$ & 0.768 \\
\hline IL4 TC/ IL6 GG & 100 & $75.6 \pm 17.0$ & 2.1 & $(-1.5-5.7)$ & 0.217 & 17 & $(17.0 \%)$ & 0.94 & $(0.67-1.32)$ & 0.720 \\
\hline IL4CC / IL6CC & 208 & $76.5 \pm 14.6$ & 3.1 & $(-1.2-7.4)$ & 0.127 & 20 & $(9.6 \%)$ & 0.48 & $(0.39-0.58)$ & $<0.001$ \\
\hline IL4 TT/ IL6 GG & 91 & $77.6 \pm 15.4$ & 4.2 & $(0.4-8.1)$ & 0.036 & 9 & $(9.8 \%)$ & 0.49 & $(0.37-0.63)$ & $<0.001$ \\
\hline IL4 CC / IL6 GG & 34 & $79.1 \pm 13.4$ & 5.2 & $(0.3-10.2)$ & 0.041 & 0 & $(0.0 \%)$ & 0.00 & - & - \\
\hline
\end{tabular}

${ }^{\dagger}$ adjusted for age, sex, hypertension, diabetes mellitus, and cardiovascular diseases. Standard errors were adjusted for study areas. eGFR $=$ estimated glomerular filtration rate. CKD = chronic kidney disease. CKD is defined by eGFR $<60 \mathrm{ml} / \mathrm{min} / 1.73 \mathrm{~m}^{2}$.

was only $1 \%$. Thus, the errors in genotyping seem unlikely to result in substantial misclassification [13], although the large number in the study population might account for the statistically significant deviation from Hardy-Weinberg equilibrium. Another limitation is the possible misclassification of CKD subjects owing to the single measurement of SCr. As our subjects were presumably healthy volunteers or health check-up examinees, their kidney function might have been stable. Thus, the possibility that a single measurement of $\mathrm{SCr}$ could result in misclassification is low. Since we lacked a replication cohort, adjustment of the p-values for the multiple comparisons, and biomarkers of inflammation, further confirmation using another cohort of subjects is needed so that there is a high chance that our study results represent a false positive finding. As this was a cross-sectional study, a prospective study is needed to further confirm the decrease in eGFR and the incident risk of CKD.

\section{Conclusions}

The functional cytokine polymorphisms IL4 T-33C (rs2070874) and IL6 C-572G (rs1800796), which are the only SNPs identified to date that affect the IL-4 and IL-
6 levels in Japanese subjects, were associated with kidney function and CKD prevalence in a large Japanese population. The IL4 -33CC and IL6 -572GG genotypes (high IL-4-and low IL-6-producing genotypes) showed better kidney function and a lower risk of CKD compared with the other variants. These differences were greater when the two genotypes were combined. This study supported the hypothesis that genetic variations in the anti-inflammatory cytokine IL4 and pro-inflammatory cytokine IL6 genes may predispose subjects to the development of CKD. Determination of the genotypes involved may prove informative for identifying individuals at a lower or higher risk of CKD. Further confirmation in another study is needed.

\section{Acknowledgements}

The authors thank Kyota Ashikawa, Tomomi Aoi and other members of the Laboratory for Genotyping Development, Center for Genomic Medicine, RIKEN, for support with genotyping, and Yoko Mitsuda, Keiko Shibata and Etsuko Kimura at the Department of Preventative Medicine, Nagoya University Graduate School of Medicine, for their technical assistance. This study was supported in part by Grants-in-Aid for Scientific Research from the Japanese Ministry of Education, Culture, Sports, Science and Technology (Nos. 17015018 and 221S0001). 


\section{Author details}

'Department of Preventive Medicine, Nagoya University Graduate School of Medicine, Nagoya, Japan. ${ }^{2}$ Department of Preventive Medicine, Faculty of Medicine, Saga University, Saga, Japan. ${ }^{3}$ Department of Health Science, Shiga University of Medical Science, Otsu, Japan. ${ }^{4}$ Department of Public Health, Nagoya City University Graduate School of Medical Sciences, Nagoya, Japan. ${ }^{5}$ Department of International Island and Community Medicine, Kagoshima University Graduate School of Medical and Dental Science, Kagoshima, Japan. ${ }^{6}$ Department of Geriatric Medicine, Kyushu University Graduate School of Medical Sciences, Fukuoka, Japan. ${ }^{7}$ Department of Preventive Medicine, Institute of Health Biosciences, University of Tokushima Graduate School, Tokushima, Japan. ${ }^{8}$ Department of Epidemiology for Community Health and Medicine, Kyoto Prefectural University of Medicine, Kyoto, Japan. ${ }^{9}$ Division of Epidemiology and Prevention, Aichi Cancer Center Research Institute, Nagoya, Japan. ${ }^{10}$ Division of Cancer Registry, Prevention and Epidemiology, Chiba Cancer Center, Chiba, Japan. ${ }^{11}$ Laboratory for Genotyping Development, Center for Genomic Medicine, RIKEN, Yokohama, Japan.

\section{Authors' contributions}

$\mathrm{RO}$ analyzed data and mainly drafted the article. KW, MN, KA, and MK were involved in drafting the manuscript and revising it critically for important intellectual content. EM, SK, MH, NT, SS, TT, KO, HH, KM, and $\mathrm{HM}$ made substantial contributions to the conception, design, and acquisition of data. $\mathrm{NH}$ and $\mathrm{HT}$ initiated the study and gave final approval of the version to be published. All the authors have read and approved the final manuscript.

\section{Competing interests}

The authors declare that they have no competing interests.

Received: 30 June 2011 Accepted: 9 January 2012

Published: 9 January 2012

\section{References}

1. Köttgen A, Pattaro C, Böger CA, Fuchsberger C, Olden M, Glazer NL, Parsa A, Gao X, Yang Q, Smith AV, O'Connell JR, Li M, Schmidt H, Tanaka T, Isaacs A, Ketkar S, Hwang SJ, Johnson AD, Dehghan A, Teumer A, Paré G, Atkinson EJ, Zeller T, Lohman K, Cornelis MC, Probst-Hensch NM, Kronenberg F, Tönjes A, Hayward C, Aspelund T, Eiriksdottir G, Launer LJ, Harris TB, Rampersaud E, Mitchell BD, Arking DE, Boerwinkle E, Struchalin M, Cavalieri M, Singleton A, Giallauria F, Metter J, de Boer IH, Haritunians T, Lumley T, Siscovick D, Psaty BM, Zillikens MC, Oostra BA, Feitosa M, Province M, de Andrade M, Turner ST, Schillert A, Ziegler A, Wild PS, Schnabel RB, Wilde S, Munzel TF, Leak TS, Illig T, Klopp N, Meisinger C, Wichmann HE, Koenig W, Zgaga L, Zemunik T, Kolcic I, Minelli C, Hu FB, Johansson A, Igl W, Zaboli G, Wild SH, Wright AF, Campbell H, Ellinghaus D, Schreiber S, Aulchenko YS, Felix JF, Rivadeneira F, Uitterlinden AG, Hofman A, Imboden M, Nitsch D, Brandstätter A, Kollerits B, Kedenko L, Mägi R, Stumvoll M, Kovacs P, Boban M, Campbell S, Endlich K, Völzke H, Kroemer HK, Nauck M, Völker U, Polasek O, Vitart V, Badola S, Parker AN, Ridker PM, Kardia SL, Blankenberg S, Liu Y, Curhan GC, Franke A, Rochat T, Paulweber B, Prokopenko I, Wang W, Gudnason V, Shuldiner AR, Coresh J, Schmidt R, Ferrucci L, Shlipak MG, van Duijn CM, Borecki I, Krämer BK, Rudan I, Gyllensten U, Wilson JF, Witteman JC, Pramstaller PP, Rettig R, Hastie N, Chasman DI, Kao WH, Heid IM, Fox CS: New loci associated with kidney function and chronic kidney disease. Nat Genet 2010, 42:376-384.

2. Yoshida T, Kato K, Fujimaki T, Yokoi K, Oguri M, Watanabe S, Metoki N, Yoshida H, Satoh K, Aoyagi Y, Nishigaki Y, Suzuki T, Nozawa Y, Yamada Y: Association of genetic variants with chronic kidney disease in Japanese individuals. Clin J Am Soc Nephrol 2009, 4:883-890.

3. Luttropp K, Lindholm B, Carrero JJ, Glorieux G, Schepers E, Vanholder R, Schalling M, Stenvinkel P, Nordfors L: Genetics/Genomics in chronic kidney disease-towards personalized medicine? Semin Dial 2009, 22:417-422.

4. Rao M, Wong C, Kanetsky P, Girndt M, Stenvinkel P, Reilly M, Raj DS: Cytokine gene polymorphism and progression of renal and cardiovascular diseases. Kidney Int 2007, 72:549-556.

5. Balakrishnan VS, Guo D, Rao M, Jaber BL, Tighiouart H, Freeman RL, Huang C, King AJ, Pereira BJ, HEMO Study Group: Cytokine gene polymorphisms in hemodialysis patients: association with comorbidity, functionality, and serum albumin. Kidney Int 2004, 65:1449-1460.
6. Carrero JJ, Park SH, Axelsson J, Lindholm B, Stenvinkel P: Cytokines, atherogenesis, and hypercatabolism in chronic kidney disease: a dreadful triad. Semin Dial 2009, 22:381-386.

7. Silverstein DM: Inflammation in chronic kidney disease: role in the progression of renal and cardiovascular disease. Pediatr Nephrol 2009, 24:1445-1452.

8. Mittal RD, Manchanda PK: Association of interleukin (IL)-4 intron-3 and IL$6-174 \mathrm{G} / \mathrm{C}$ gene polymorphism with susceptibility to end-stage renal disease. Immunogenetics 2007, 59:159-165.

9. Tindall EA, Severi G, Hoang HN, Ma CS, Fernandez P, Southey MC, English DR, Hopper JL, Heyns CF, Tangye SG, Giles GG, Hayes VM: Australian Prostate Cancer BioResource: Comprehensive analysis of the cytokine-rich chromosome 5q31.1 region suggests a role for IL-4 gene variants in prostate cancer risk. Carcinogenesis 2010, 31:1748-1754.

10. Komatsu Y, Tai H, Galicia JC, Shimada Y, Endo M, Akazawa K, Yamazaki K, Yoshie H: Interleukin-6 (IL-6)-373 A9T11 allele is associated with reduced susceptibility to chronic periodontitis in Japanese subjects and decreased serum IL-6 level. Tissue Antigens 2005, 65:110-114.

11. Buckham TA, McKnight AJ, Benevente D, Courtney AE, Patterson CC, Simmonds M, Gough S, Middleton D, Borrows R, Maxwell AP: Evaluation of five interleukin genes for association with end-stage renal disease in white Europeans. Am J Nephrol 2010, 32:103-108.

12. Hamajima N, J-MICC Study Group: The Japan Multi-Institutional Collaborative Cohort Study (J-MICC Study) to detect gene-environment interactions for cancer. Asian Pac J Cancer Prev 2007, 8:317-323.

13. Wakai K, Hamajima N, Okada R, Naito M, Morita E, Hishida A, Kawai S, Nishio K, Yin G, Asai Y, Matsuo K, Hosono S, Ito H, Watanabe M, Kawase T, Suzuki T, Tajima K, Tanaka K, Higaki Y, Hara M, Imaizumi T, Taguchi N, Nakamura K, Nanri H, Sakamoto T, Horita M, Shinchi K, Kita Y, Turin TC, Rumana N, Matsui K, Miura K, Ueshima H, Takashima N, Nakamura $Y_{,}$ Suzuki S, Ando R, Hosono A, Imaeda N, Shibata K, Goto C, Hattori N, Fukatsu M, Yamada T, Tokudome S, Takezaki T, Niimura H, Hirasada K, Nakamura A, Tatebo M, Ogawa S, Tsunematsu N, Chiba S, Mikami H, Kono S, Ohnaka K, Takayanagi R, Watanabe Y, Ozaki E, Shigeta M, Kuriyama N, Yoshikawa A, Matsui D, Watanabe I, Inoue K, Ozasa K, Mitani S, Arisawa K, Uemura H, Hiyoshi M, Takami H, Yamaguchi M, Nakamoto M, Takeda H, Kubo M, Tanaka H, J-MICC Study Group: Profile of participants and genotype distributions of 108 polymorphisms in a cross-sectional study of associations of genotypes with lifestyle and clinical factors: A Project in the Japan Multi-institutional Collaborative Cohort (J-MICC) Study. J Epidemiol 2011, 21:223-235

14. Okada R, Suzuki K, Ito Y, Nishio K, Ishida Y, Kawai S, Goto Y, Naito M, Wakai K, Hamajima N: Association between decreased kidney function and endotoxin receptor CD14 C-159T polymorphism among Japanese health check-up examinees. Ren Fail 2007, 29:967-972

15. Nakashima H, Miyake K, Inoue Y, Shimizu S, Akahoshi M, Tanaka Y, Otsuka T, Harada M: Association between IL-4 genotype and IL-4 production in the Japanese population. Genes Immun 2002, 3:107-109.

16. Hamajima N, Naito M, Kondo T, Goto Y: Genetic factors involved in the development of Helicobacter pylori-related gastric cancer. Cancer Sci 2006, 97:1129-1138.

17. Oda K, Tanaka N, Arai T, Araki J, Song Y, Zhang L, Kuchiba A, Hosoi T, Shirasawa T, Muramatsu M, Sawabe M: Polymorphisms in pro- and antiinflammatory cytokine genes and susceptibility to atherosclerosis: a pathological study of 1503 consecutive autopsy cases. Hum Mol Genet 2007, 16:592-599.

18. Ohnishi Y, Tanaka T, Ozaki K, Yamada R, Suzuki H, Nakamura Y: A highthroughput SNP typing system for genome-wide association studies. J Hum Genet 2001, 46:471-477.

19. Matsuo S, Imai E, Horio M, Yasuda Y, Tomita K, Nitta K, Yamagata K, Tomino $Y$, Yokoyama H, Hishida A, Collaborators developing the Japanese equation for estimated GFR: Revised Equations for Estimated GFR From Serum Creatinine in Japan. Am J Kidney Dis 2009, 53:982-992.

20. National Kidney Foundation: K/DOQI clinical practice guidelines for chronic kidney disease: evaluation, classification, and stratification. Am J Kidney Dis 2002, 39:51-266.

21. von der Thüsen $J H$, Kuiper J, van Berkel TJ, Biessen EA: Interleukins in atherosclerosis: molecular pathways and therapeutic potential. Pharmacol Rev 2003, 55:133-166.

22. Marousi S, Ellul J, Antonacopoulou A, Gogos C, Papathanasopoulos P, Karakantza M: Functional polymorphisms of interleukin 4 and interleukin 
10 may predict evolution and functional outcome of an ischaemic stroke. Eur J Neurol 2011, 18:637-643.

23. Müller-Steinhardt M, Fricke L, Müller B, Ebel B, Kirchner H, Härtel C: Cooperative influence of the interleukin- 6 promoter polymorphisms $-597,-572$ and -174 on long-term kidney allograft survival. Am J Transplant 2004, 4:402-406.

24. Smallwood $L$, Allcock $R$, van Bockxmeer $F$, Warrington $N$, Palmer $L$, lacopetta B, Norman PE: Polymorphisms of the interleukin-6 gene promoter and abdominal aortic aneurysm. Eur J Vasc Endovasc Surg 2008, 35:31-36.

25. Imai E, Horio M, Yamagata K, Iseki K, Hara S, Ura N, Kiyohara Y, Makino H, Hishida A, Matsuo S: Slower decline of glomerular filtration rate in the Japanese general population: a longitudinal 10-year follow-up study. Hypertens Res 2008, 31:433-441.

26. Terry CF, Loukaci V, Green FR: Cooperative influence of genetic polymorphisms on interleukin 6 transcriptional regulation. $J$ Biol Chem 2000, 275:18138-18144.

\section{Pre-publication history}

The pre-publication history for this paper can be accessed here: http://www.biomedcentral.com/1471-2369/13/2/prepub

doi:10.1186/1471-2369-13-2

Cite this article as: Okada et al:: Pro-/anti-inflammatory cytokine gene polymorphisms and chronic kidney disease: a cross-sectional study. BMC Nephrology 2012 13:2.

\section{Submit your next manuscript to BioMed Central} and take full advantage of:

- Convenient online submission

- Thorough peer review

- No space constraints or color figure charges

- Immediate publication on acceptance

- Inclusion in PubMed, CAS, Scopus and Google Scholar

- Research which is freely available for redistribution

Submit your manuscript at www.biomedcentral.com/submit
C Biomed Central 